\title{
Introduction
}

\section{THE PURPOSE}

This book should really be considered as epistemology, especially as we wish to construe that term broadly. ${ }^{1}$ It rests on ontology and takes aim at methodological foundations. The object is to re-examine the scientific standing of structural econometrics as developed by the founders of econometrics (Frisch and Tinbergen) and extended by Haavelmo and the Cowles modellers (particularly Klein) during the period 1930-60.

The early econometricians tended to believe they could test economic theories and discover scientific laws analogous to the laws of physics and natural science. The writers who have examined the history of econometrics have tended to accept this project more or less uncritically. By contrast, we consider this misguided, and based on philosophical error. Certainly, in our view, econometrics can contribute empirical insights that will advance the development of economic theory, and it can specify and identify reliable projectible relationships, but, as we shall explain, these are not the same as the scientific laws of physics, and they are specific to particular periods of history. But they do exist.

The book can be seen as a response to Caldwell's (1982, p. 216) challenge. The quotation from Caldwell suggests integrating economic methodology and philosophy with econometrics. It is still applicable and even more worthy of consideration today.

Spanos (2007, p. 2) elevated the philosophy of econometrics to primacy of place in the philosophy of economics, as the study of 'general principles, strategies and philosophical presuppositions that underlie empirical modeling'; the aim being to understand how to achieve 'learning from data'. This concerns methodology, of course, but also ontology and epistemology. How can we transmute 'noisy and incomplete data into reliable evidence'? We have to know that the data are actually genuine (or at least adequate) instances of the variables of the theory or hypothesis. So we have to understand where the data come from, which is to say, we have to have some sense of the reliability and working of the data generating process. Econometricians still face unresolved problems in bridging the gap between data and theories after all these years! But without such a 
bridge, the most sophisticated technical methodology will be swept away in a flood of errors.

This worries Spanos (2007), who considers that economic methodology has failed to address the core issue: the theory-data gap in econometrics. ${ }^{2}$ Instead, so far, the literature has focused primarily on a variety of less significant issues such as the status of assumptions, the structure of theories, falsification versus verification, Kuhnian paradigms versus Lakatosian research programs, the sociology of scientific knowledge, realism versus instrumentalism, 'post-modernist' philosophy, and so on (see Backhouse, 1994; Blaug, 1980; Dagum, 1986a; 1986b; 1995; Davis et al., 1998; Maki, 2001; 2002; Milberg, 1993; 2007; Redman, 1991). Even in methodological discussions of economic theories in relation to reality, econometrics tends to be neglected (Caldwell, 1982) or misrepresented (Lawson, 1997). Economic methodology itself seems to have problems. When assessing recent work, Hands (2001) contends that philosophy of science is 'currently in disarray on almost every substantive issue' and provides 'no reliable tool for discussing the relationship between economics and scientific knowledge'. But Spanos (2007) thinks this sort of comment is unhelpful and believes that some writing in the current philosophy of science, focusing on 'learning from data' (see Chalmers, 1999; Hacking, 1983a; Mayo, 1996), will contribute toward improving the credibility of economics as an empirical science.

The state of econometric practice bothers McCloskey (1996, pp. 30-33), who has judged that:

the first tragedy arising from the pride of the 1940s is called 'statistical significance. [It] ruins [econometrics]. The problem comes, not in 'estimation' but in 'testing'. The 'testing' makes no sense at all if it is seen, as it usually is, as answering the scientific questions 'How large is this effect?' or, what is the same thing, 'Does it matter for science?

In rare circumstances the statistical significance of an estimate might be of small scientific interest. In the overwhelming proportion of its uses in economics, it is completely irrelevant. All of modern econometrics has to be done over again.

Methodological debates in econometrics are almost as long-standing as the discipline itself (see Epstein, 1987; Gilbert, 1988; Morgan, 1990a; and Qin, 1993). Boland (1982, pp.4-5) argued that

presentations of methodology in typical econometrics articles are really nothing more than reports about the mechanical procedures used, without any hint of the more philosophical questions. The so-called methodological critiques turn out to be critiques of the statistical definitions or statistical tests used in the study in question. Similarly, methodological issues turn out to be questions of 
whether to use 'comparative statics' or whether to use 'a moving average' or 'discrete observations'.

At the time it seemed easier to practice the science than to describe how one was doing it. 'Get on with the job' was the message sent by mainstream econometricians.

The epistemological status of the econometric approach that we propose, however, is different from what might be considered, in fact, to be diametrically opposed to that generally found in the discipline. The polar nature of this difference lends itself exquisitely to the debate on certain fundamental aspects of neoclassical econometrics.

Our point of departure is the research agenda as it was defined by the founders' editorial in the first issue of Econometrica in 1933, where Frisch ${ }^{3}$ (1933, p. 1) eloquently expounded the hopes and expectations for econometrics, and hailed it as:

The unification of the theoretical-quantitative and the empirical-qualitative approach to economic problems with a constructive and rigorous 'thinking' similar to that which has come to dominate in the natural sciences.

Pesaran and Smith (1992, p. 1) commented on this:

We have come a long way since the appearance of the first issue of Econometrica, and yet Frisch's call for the unification of theory and measurement is as relevant today as it then was.

Morgan (1990a, p. 264) has concluded from her history of econometrics study that 'by the 1950s the founding ideal of econometrics, the union of mathematical and statistical economics into a truly synthetic economics, had collapsed'.

Structural econometrics, as we understand it, ends in 1960; our study, of course, examines later developments. ${ }^{4}$ But the econometrics that we wish to rethink and (in part) revive underwent a major change at about this date. 1960 was the date of the exit of Frisch and Haavelmo from econometrics. ${ }^{5}$

First, Haavelmo (1958) contended that weak theoretical economic foundations rendered suspect the policy value of most econometric models. Then Frisch (1961) chose not to mention econometrics in a survey of types of economic forecasting methods. To paraphrase Frisch, the models had become 'hollow numerical exercises' because they 'failed to represent the effective institutional and political constraints on feasible economic policies'. Our interest is to ask what should and can we learn from the period of history leading up to this point with respect to present and future econometric model building? 
Haavelmo (1944) played a crucial role in first demonstrating the need for an explicit 'probabilistic model' for econometric estimation and inference, and then in advocating the 'Fisherian model' as an ideal for this particular purpose, emphasizing the importance of inference and testing in applied economic research. Subsequent work at the Cowles Commission demonstrated that the now standard 'Neyman-Pearson' inferential framework could be applied in econometric regression models.

Malinvaud (1988, p. 197) has claimed that the Cowles Project 'essentially stands untouched and no doubt or questioning can be expressed'. Our objective is to determine first whether or not, and in what sense, the Cowles Project, as conceived by the founders and Haavelmo and developed by the Cowles Commission, is appropriate for the purpose for which it was originally designed. Second, since this is partly an empirical question, we need a methodological framework for empirical study. So we have developed such a framework - the unifying thread of this work - that can overcome most of the methodological problems of structural econometrics. But it requires a new approach to theory.

The Cowles Project, to paraphrase Epstein (1987), raised such high hopes by proposing its structural estimation methodology that the lack of agreed findings is in some ways astonishing. This lack of agreement actually reflects a genuine 'epistemological puzzle'. The problem arises partly from disagreement over how to capture the basic structure that underlies the economic system, including problems of how to select models, both of which undermine the ambition to prescribe how to manipulate the economic system towards stability. But it also arises partly from disagreement over whether the world is, in fact, a stochastic environment that can be captured by superimposing a statistical disturbance on a deterministic model provided by economic theory. In this view, the probabilistic element is admitted only at a second stage, an afterthought following the deterministic first stage, provided in the mainstream approach by the theory of rational choice. Boland (1982, p.122) argued that 'this conception of the world can be very misleading and thus requires critical examination'. ${ }^{6}$

How do the ideas developed by Haavelmo and the Cowles Group in the 1940s and 1950s stand today? Should their approach be discarded and replaced, as modern critiques have argued? A careful and critical examination of the methodological issues should help us understand how the Cowles Project developed, and how it can be further refined, hopefully providing insight into some of the principal methodological points at issue today. 


\section{THE SETTING OF THE PROBLEM}

\section{The Complaint}

The Complaint here charged that neoclassical economic theory arguably provides the ontological basis (the rational individual) and the corresponding individualistic methodology of the modern econometrics that has come to replace the Cowles Project. The result is that neoclassical based econometrics, which functions at the level of appearances and events, fails to develop any insight into deep structures - it interprets whatever it sees as individuals choosing with some degree of (perhaps bounded) rationality. It simply relates observables to one another, putting choices and actions together into equilibrium patterns.

Neoclassical model builders make no effort to reach through to a deeper level. Hollis and Nell (1975), Lawson (1997) and Nell (1998a) have all argued that neoclassical theory should be rejected as empiricist and deductivist. Of course, this has been argued before, so while the charge is not at all new, it is still as controversial as ever. And it seems clearly true of a great deal of what passes for applied econometric research. However, it is not so clear that mainstream economic theory can be both empiricist and deductive at the same time.

Correlations are precisely 'Humean' constant conjunctions, to use Nell's expression, and the search for them is the practice of relating observables to one another. When neoclassical econometrics seeks to go beyond good correlations and impute causality, the notion it employs - Granger causality - is strictly Humean, depending as it does, mechanically, on temporal priority. Yet, as Nell (1998a) argued, temporal priority is neither necessary nor sufficient for causality, using the concepts in their normal sense.

Boland (1982, p. 122) argued that

virtually every applied neo-classical model today is a stochastic model. The problem with the concept stochastic, or more generally, with the 'doctrine of stochasticism' - an ontology that asserts that realism means being stochastic - is that it takes too much for granted without reason or evidence. Some economists are fond of claiming that the world is a stochastic environment (e.g., Vernon Smith, 1969); thus technically no model is ever refuted or verified, and hence there could not be any chance of our construing one as a refutation or a verification of a theory.

Consider the role of stochasticism in mainstream economics. Boland (1982, p. 122) argued that 'stochasticism involves model building, as it requires an explicit modeling assumption that might be false, so it should not be taken for granted'. Let's see how modern econometricians deal with this. 
Following Nell's (1998a) approach and conceptual analysis, one could argue that there are two worlds (though Nell doesn't so label them): the real world that we observe and the model world of the theory or mathematical model that we construct. The model will always abstract from reality. But sometimes the theory requires that the model consist of idealized actors or circumstances or behavior, so that nothing real could ever closely correspond. This raises special problems that we shall discuss later. When we say the theory (or model) is true, we mean that the real and the model worlds exactly or at least adequately correspond. Many will argue that there are obvious reasons why, even with good theories, the correspondence will not be exact (for example, errors of measurement, irrational human behaviour, etc.). For these reasons, modern economists build stochastic models that explicitly accommodate the stochastic nature of the correspondence (see Boland, 1982, pp. 122-3). For example, we can assume that the measurement errors leave the observations in a normal random distribution about the true values of the model world. This means that the correspondence itself is the stochastic element of the model.

In Haavelmo's perspective, contrary to that of modern econometricians, it is the 'model that is stochastic', rather than the 'world' or the 'environment'. Any test of a stochastic model is as much a test of the assumed correspondence as it is of the theory itself. Modern econometricians do not seem to be willing to go all the way with Haavelmo and thus still to see a possibility of stochastic models being helpful in the assessment of exact theories and models (see Spanos, 1989; 2007; Davis, 2000). It could also be said that stochastic models follow from a methodological decision not to attempt to explain anything completely.

Boland (1982, p. 123) argued that

one can choose to see the world as being necessarily stochastic only if one assumes beyond question that one's model (the shot at the real world target) is true (and fixed) and that the variability of the correspondence is due entirely to the movements of the target (the real world). Thus, stochasticism can be seen to put the truth of our theories beyond question. There is a serious element of potential intellectual dishonesty in asserting that the environment is stochastic.

Neoclassical econometrics is a major digression from Haavelmo's econometric thinking and the founders' 'unification vision'.

Furthermore, Bonnafous $(1972 ; 1989)$ argued that in economics as in any field dealing with the real world, the real issue is not 'simplification', but how to simplify without losing the relationship to real-world phenomena. In more general terms, simplification is a necessary part of thought, because simplification results from abstraction. As Krugman 
(1997) observed, as soon as one is engaged in thinking - that is, in forming concepts - an abstraction results. But, as Nell (1998a) put it, 'abstraction' is not 'idealization'?

Contemporary currents in scientific thought allow us to abandon the (essentially metaphysical) idea of a necessary and pre-established adequacy between mathematics and reality. To paraphrase Bonnafous (1972, p.11), the world of inexact science, in particular, does not appear to be organized according to mathematical laws. Furthermore, it is interesting to observe that, in the nineteenth century, at the same time that the idea of a universal truth provided by mathematics was discredited by the emergence of alternative axiomatic systems, because of Walras, a narrow view of rationality rapidly gained dominance in economic science, subscribing to a Platonic and Cartesian approach to science. Leontief (1984a, 1984b) argued that such work in pure economics continues to be widely pursued today.

\section{The Vision}

The vision we propose here puts 'methodological institutionalism' in place of 'methodological individualism'. Hollis and Nell (1975) had already both exposed and explained the methodological deficiencies of modern econometrics, before they had become widely realized. Moreover, Hollis and Nell's framework and later Nell (1998a) suggested a way of fixing the problems. The founders of econometrics, Haavelmo and the Cowles econometricians, held a vision of the real world - first expressed in the Cowles Project that provided the epistemic foundation for the econometric field in the 1940s. This vision provides a perspective that is ontologically incompatible with the contemporary view of modern econometricians that developed in the late 1970s and early 1980s.

The history of econometric thought will show that the modern critiques, based as they are on methodological individualism and positivism, have turned into ontological and epistemological failures, proffering inadequate criteria for what exists, and for what we know. We shall argue that Klein's methodological structuralism and Nell's methodological institutionalism offer a new approach, an ontological turn, so to speak, that ensures that socioeconomic reality, understood through fieldwork, will be what defines the terms of the model, and not the other way around.

Nell (1998a) argued that models have to refer to what actually exists; that is what is meant by realism. But models also have to exhibit relationships similar to those in reality, yet in a form that can be manipulated or analysed mathematically. That is how models help advance understanding. But model building cannot be allowed to succumb to the lure of 
scientism. In particular, a sound epistemology tells us that the social order is necessarily 'open'; that is, it cannot be circumscribed and summed up in a deterministic model. Nor can it be described in terms of stochastic regularities of the sort presupposed by modern econometricians (see also Lawson, 1997, pp. 76-7; Lewis and Runde, 1999, pp. 38-9).

The main argument of the book is that structural econometrics can be redeveloped on the basis of rereading Haavelmo within Hollis and Nell's (1975) framework and Nell's (1998a) methodological institutionalism. We think this may prove to be the most fruitful empirical approach in economics.

\section{OUTLINE OF THE BOOK}

It is not our intention to call into question the basic principles of structural econometrics itself. To be critical does not mean to disparage or to destroy in the sense of Lucas's critique or Sims's alternative methodology, but to be lucid and vigilant and ready to call something in question when appropriate. It is 'deconstruction' for better building, as Jacques Derrida would have said!

The book consists of three parts and a general conclusion. Part I focuses on rethinking the scientific foundations of structural econometrics. The main argument of Part $\mathrm{I}$ is that there are good reasons for considering Hollis and Nell's (1975) framework as an epistemological foundation for reconstructing structural econometrics, a foundation that complements and extends the original ideas of Haavelmo.

Part I consists of six chapters. Chapter 1 restates and adapts the arguments of Hollis and Nell, shifting the focus from economic theory to econometrics. Chapter 2 connects the Hollis and Nell line of argument with Haavelmo's initial and later papers, revealing a surprising degree of overlap. Chapter 3 examines whether and how claims to have established scientific knowledge can be justified, and this calls for a review of the longstanding arguments over induction, culminating in the recent revival of this literature in the work of Mayo and Spanos (2010), focusing it directly on statistics and econometrics. Chapter 4 presents a justification of scientific laws for the physical sciences (resolving the philosophical problem of induction). The argument is an extension of Strawson's 'descriptive metaphysics' and runs along Kantian lines. Chapter 5 then adapts this approach to economics, first justifying 'economic laws' and then displaying the differences between them and the 'laws' of the physical sciences, finally relating this discussion to somewhat similar ideas in critical realism. Chapter 5's appendix presents a brief discussion of Plato on the economic 
principles underlying the formation of a socio-economic system. Chapter 6 defines the three conditions for a successful model - theoretical coherence, relevance (how it applies to the real world), and measurement - summing these up in the methodological triangle-circle (MTC) diagram.

Part II is methodological. The current critiques of the methodological foundations of structural econometrics are direct consequences of implicitly accepted but seriously flawed views of the appropriate foundations of econometrics, grounded in neoclassical thinking. Chapter 7 shows that within the neoclassical framework it is possible to improve the performance of a model on any one of these conditions only at the expense of worsening its performance on at least one of the others; the MTC diagram is then used to analyse the major critiques and commentators on the foundations of econometrics (Malinvaud, Lucas, Sims, Leamer, Hendry), contrasting their views with the unification scheme of the founders. Chapter 8 advances the methodological considerations presented so far, re-examining probability and the error term; and then applies the approach to stochastic methods, arguing that it is a mistake to think of the world as stochastic; rather, it is the methods that are stochastic, and understanding this helps us to distinguish between reliable and volatile relationships. Chapter 9 examines two treatments of Haavelmo's probabilistic approach (Davis, 2000; Spanos, 1989), both of whom consider questions of statistical adequacy, then turns to a critical study of Los's (2001) rejection of the probability approach, following this with an exploration of Foley's (2005) Laplacian rethinking of the foundations of probability. We argue that each author has something to offer, but that an important common concern, which was also central to Haavelmo's work - namely the apparently inherent unpredictability of much economic behaviour - may have to be approached in terms of uncertainty, rather than probability. This echoes Keynes. Then all four are subjected to analysis using the MTC diagram, further developing the thesis that models rather than the world are stochastic. Our approach calls for all three to be respected: coherence, measurability and relevance - and their possible relationships must be articulated. This, we think, was part of the vision of the founders of econometrics, especially Haavelmo, and the approach of Klein and Nell can be seen as an elaboration of what might be called a new econometric playing field.

Part III consists of two chapters. Chapter 10 presents our distinctive methodological contribution: a blend of fieldwork and conceptual analysis designed to ensure that our models are well grounded in reality but at the same time are conceptually coherent. Chapter 11 then turns to specification, and outlines a number of elements that will be needed in developing a good macroeconometric model of an advanced economy, covering money, 
inflation, expectations, together with the basic relations of output and employment, consumption and income, investment, profits and finance, showing how we can distinguish reliable from volatile relationships, and suggesting ways in which this approach can be developed further.

The general conclusion sums up the main arguments developed in the book. It also offers concluding comments on methodology and suggestions for future directions in the study of macroeconometric model building.

Finally, each argument is part of the whole picture, and each is linked with the others. No parts of the book really stand alone; the book as a whole presents a picture of econometrics as a whole. Of course there are many weaknesses and even our best arguments might have been better; but the whole picture suggests that the founders were on the right track: econometrics really can tell us how the economy works and how we can make it work better.

\section{NOTES}

1. The term here is defined by Bitsakis (1987, p. 389) as follows: 'epistemology is not a particular science. It is a discourse about science. It investigates the foundations, status, classification and development of the sciences, the function of internal and external factors determining their development, the relationships between theory and experiment, the nature of scientific crisis and revolutions, the status of scientific truth'. For a comprehensive discussion of epistemological issues in economics see Hollis (1987), Cecconi (2000, particularly chs I, IV and V) and Dupuy (2004).

2. Spanos (2007, p. 2) argued that 'discussions of econometric methodology have been primarily "local" affairs (e.g., Granger, 1990; Hendry, 2000; Leamer, 1988 among others) ... where no concerted effort was made to integrate the discussions into the broader philosophy of science discussions concerning empirical modeling'. He pointed out that there are some notable recent exceptions like Hoover (2002; 2006), Keuzenkamp (2000) and Stigum (2003).

3. Aldrich (1989, p.33) argued that Frisch's ideas on structure 'were embodied in Haavelmo's 1944 probability approach and his ideas on dynamics clearly influenced Samuelson's 1947 Foundations of Economic Analysis, the works which above all others codified the methodological discoveries of those years'. For a discussion of Frisch's role in econometrics see Tinbergen (1974). For an account of the failure of Frisch's vision, see Lail (1993).

4. For a comprehensive and detailed account of the history of econometrics see Epstein (1987), Gilbert (1988), Morgan (1990a) and Qin (1993). Here we are concerned to bring out the important and still unresolved problems which the founders struggled with and which are highlighted in the Hollis and Nell critique. We will present in Chapter 7 some notes on the history of econometrics. These notes clearly do not aim to be comprehensive, but only to trace some trends in the development of econometrics.

5. The exit of the Oslo professors from econometrics is still an open question in the history of econometric thought. For further details see Epstein (1987, ch. 4).

6. For an account of 'stochasticism' and econometrics see Boland (1977; 1982; 2000) and also Chapter 8 of this book.

7. We will further clarify the difference between abstraction and idealization in Chapter 6 . 